\title{
Short and Long-run Effects of Macroeconomic Variables on the Spanish Agricultural Sector
}

Monia Ben KAABIA and José M. GIL

Unidad de Economia Agraria - SIA - DGA

Apdo. 727; 50080 Zaragoza (Spain)

\begin{abstract}
In this paper, the effect of some relevant macroeconomic variables on Spanish agricultural prices and exports is analysed. The methodological approach used is based on the cointegration procedure making the distinction between short- and long-run effects possible. A eight variables system in real terms is specified. Long-run analysis indicates that money income neutrality as well as agricultural prices homogeneity hold. Short-run dynamics has been analysed by specifying a Structural Vector Error Correction Model. Main results indicate that, in general terms, agricultural variables do not significantly affect macroeconomic variables. In the very short run farmers will benefit from increases of money and general prices while over longer horizons the agricultural terms of trade get worse.
\end{abstract}

Key words: macroeconomics, agriculture, cointegration; Spain, short and long-run. 


\section{INTRODUCTION}

Changes in the macroeconomic policy have become increasingly significant within the agrofood sector as agriculture has become more capitalized and more dependent on international markets, then being more vulnerable to variations in interest rates, exchange rates and international growth rates. As a consequence, since the mid seventies, a number of theoretical and empirical studies have analysed the impact of macroeconomic variables on the relative performance of the agricultural sector. In the early studies, macroeconomic variables (income, interest rate, exports,...) were introduced as purely exogenous in agricultural sector models. It was considered that the agricultural sector was a closed system, being only influenced by a few general economic variables (In and Mount, 1994).

The paper by Schuh (1974) could be considered as the starting point of a second group of studies emphasizing the role of exchange rate in explaining agricultural variable fluctuations. In a partial equilibrium framework and considering the exchange rate as an exogenous variable, Chambers and Just (1979, 1981), Longmire and Morey (1983), and Batten and Belongia (1986) provide empirical evidence of such an effect while other studies conclude that exchange rate movements have little effect on the variability of real commodity prices (Collins et al. 1980). However, these empirical investigations neglect not only the possible effect of exchange rate changes on other macroeconomic variables (which can influence agricultural prices and exports indirectly) but also the effects of other macroeconomic variables (such as interest rates) both on exchange rate and agricultural variables. In this context, Chambers (1984) develops a general equilibrium model in order to analyse the effect of macroeconomic variables on agricultural trade where the exchange rate, income, interest rate as well as usual agricultural variables are treated as endogenous. This author concludes that tight monetary policy hurts the agricultural sector as a result of exchange rate appreciation and rising interest rates.

Finally, it is possible to identify a third group of papers dealing with the analysis of the dynamic linkages between monetary variables and the agricultural sector. Among this group of studies, considerable attention has been paid to the reaction of agricultural and nonagricultural prices to monetary shocks. The question of money neutrality in the agricultural sector, and the speed of price adjustments, has been considered of central importance for policy analysis (Bordo, 1980; Tweeten, 1980, Bessler and Babula, 1987; Devadoss and 
Meyers, 1987; Taylor and Spriggs, 1989; Robertson and Orden, 1990; Larue and Babula, 1994; Dorfman and Lastrapes, 1996, among others).

Results from most of the above mentioned studies, although mainly related to the United States and Canada ${ }^{1}$, substantially differ from each other and, in many cases, they are even contradictory. There exist alternative explanations for such differences: samples are not homogeneous, the number of variables included differs as well as their treatment as endogenous or exogenous, and the different methodological approaches used. However, there seems to exist a consensus on the fact that models analysing macroeconomic linkages to the agricultural sector should include the more relevant macroeconomic variables of the country being analysed and should treat them as endogenous (Devadoss et al., 1987; Taylor and Spriggs, 1989; Denbaly and Torgerson, 1991; Thraen et al., 1992; In and Mount, 1994; among others).

Partly for this reason, most of the analyses on this topic have recently been conducted using Vector Autoregression (VAR) models. In VAR models all variables are considered endogenous. Moreover, it is possible to calculate the short-run responses of a shock in one variable in the system on any other variable offering a convenient way to characterize data without having to involve economic theory to restrict the dynamic relationships among variables. Cooley and LeRoy (1985), among others, have criticized the usefulness of such an atheoretical approach for policy analysis. To overcome this problem "Structural" VAR (SVAR) models have been used (Bernanke, 1986, Sims, 1986 and Blanchard and Quah, 1989) which allow the researcher to specify and test restrictions based on economic theory prior to calculating the impulse response functions (Orden and Fackler, 1989).

Finally, recent developments on time series analysis have modified the econometric framework to analyse the relationships between macroeconomic variables and the agricultural sector. The concepts of non-stationarity and cointegration have become very popular and have to be explicitly tested to properly specify an econometric model. In this new context, Johansen (1988) and Johansen and Juselius (1990, 1992 and 1994) provide an interesting methodology that allows the researcher to distinguish between the short and the long run. On the one hand, it is possible to identify the long-run structural relationships among a set of variables and how variables in the system adjusts to deviations from such long-run equilibrium relationships. On the other, it is possible to calculate the impulse response 
functions in a similar way to that in the SVAR models. This distinction is useful as economic restrictions are considered long run in nature while it is also interesting, for policy analysis, to know how the system adjust to disequilibrium.

The objective of this paper is to use recent developments in time series analysis to explain the relationships between macroeconomic variables and the agricultural sector in Spain. Special attention is paid to the distinction between long-run structural relationships and short-run dynamics. The paper is one of the first attempts to analyse such relationships in Spain.

The paper is organized as follows. The data used in this study are described in section 2 as well as results from non-stationary tests. Long-run equilibrium relationships are analysed in section 3. The short-run dynamics is considered in section 4. Finally, some concluding remarks are outlined.

\section{DATA AND METHODOLOGICAL APPROACH}

In order to carry out the empirical analysis of the linkages between macroeconomic variables and the agricultural sector, two blocks of variables have been considered. The first one is the macroeconomic block which contains the more relevant macroeconomic variables: 1) real effective exchange rate (ER) (the real multilateral exchange rate ${ }^{2}$ taking into account world and Spanish consumer price indices); 2) the real money supply (RM) (money supply ${ }^{3}$ divided by the consumer price index); 3) interest rate (R) (the three-month money market interest rate); 4) inflation expressed as consumer price index in first differences ( $\Delta \mathrm{P})$; and 5 ) real gross domestic product $(\mathrm{Y})$. The second one is the agricultural block, which includes the following variables: 1) real farm input prices (RIP); 2) real farm output prices (ROP) (real farm input prices and real farm output prices are calculated as nominal prices divided by the consumer price index) and 3) real agricultural exports (AX) ${ }^{4}$ (exports value divided by the agricultural exports price index).

These variables were chosen because it was felt that they would capture the most important relationships between both sectors. Besides, as the sample period is limited, it has been attempted to use as few variables as possible. Quarterly data from 1978:1 to 1995:4 are used. All variables are in logarithms, except for the interest rate which is in a percentage form 
and is divided by one hundred to make the estimated coefficients comparable with logarithmic changes. Finally, all variables have been deseasonalised ${ }^{5}$.

Time series univariate properties have been examined by using unit root tests. As in small samples such tests have limited power (Blough, 1992), two alternative tests developed by Dickey and Fuller (1979, 1981) (DFA) and Kwiatkowski et al.(1992) (KPSS) have been applied. Both tests indicated that all variables were $\mathrm{I}(1)^{6}$

Thus, the methodological approach used in this paper consists of three steps: first, the Johansen's (1988) multivariate contegration procedure is used to test if variables are cointegrated; second, cointegration vectors are identified as long-run meaningful economic relationships; finally, impulse response functions are computed to analyse short-run dynamics

\section{LONG-RUN ANALYSIS}

The starting point of Johansen's procedure is the following reformulation of a VAR(k) into a Vector Error Correction Model (VECM):

$$
\Delta \mathrm{Z}_{\mathrm{t}}=\Phi \mathrm{D}_{\mathrm{t}}+\Pi \mathrm{Z}_{\mathrm{t}-1}+\sum_{\mathrm{i}=1}^{\mathrm{k}-1} \Gamma_{\mathrm{i}} \Delta \mathrm{Z}_{\mathrm{t}-\mathrm{i}}+\varepsilon_{\mathrm{t}}
$$

where $Z_{t}$ is a px1 vector of endogenous variables in the system; $A_{i}, i=1,2 \ldots k$ is a (pxp) matrix of short-run parameters, being $k$ the number of lags; $\Pi$ is a $(p \times p)$ matrix of long-run parameters; $D_{t}$ is a $(m \times 1)$ vector of deterministic terms (a constant, a linear term, seasonal dummies, intervention dummies, etc...); and $\varepsilon_{\mathrm{t}}$ is a vector of errors which are assumed to be i.i.d Gaussian processes, that is:

$$
\begin{aligned}
& E\left(\varepsilon_{t}\right)=0 \\
& E\left[\varepsilon_{t} \varepsilon_{s}\right]= \begin{cases}0 & \text { for all } \mathrm{t} \\
\Sigma & \text { if } \mathrm{t} \neq \mathrm{s}\end{cases}
\end{aligned}
$$

where $\Sigma$ is a $(\mathrm{p} \times \mathrm{p})$ positive-definite covariance matrix.

As series in $Z_{t}$ are $I(1)$, the right and left side in (1) will be only balanced if such series are cointegrated, that is, if $\Pi \mathrm{Z}_{\mathrm{t}-1}$ is stationary. Following Johansen's procedure, testing the 
hypothesis of cointegration consist of testing the hypothesis $H_{r}: \operatorname{rank}(\Pi) \leq r(r=0,1, \ldots, p-1)$. If $\Pi$ is of full rank $(r=p)$ then $Z_{t}$ is stationary variables and a VAR model in levels should be specified. A rank of zero implies that $\Pi$ contains no long-run information, and a VAR(k-1) in differences would be the correct specification. Finally, if $\operatorname{rank}(\Pi)=r, 0<r<p$, then there are $r$ stationary linear combinations of variables (r cointegration vectors). Under this condition, $\Pi$ can be written as the product of two matrices $\Pi=\alpha \beta^{\prime}$, where $\alpha$ and $\beta$ are matrices of dimension $p \times r$. In this case $Z_{t}$ is said to be cointegrated of order one $[C I(1,1)] ; \beta$ is a matrix of long-run coefficients such that the term $\left(\beta^{\prime} \mathrm{Z}_{\mathrm{t}-1}\right)$ represents the $(\mathrm{r})$ cointegration relationships in the multivariate model which ensure that the $Z_{t}$ converge to their long-run steady-state solutions; and $\alpha$ represents the speed of adjustment to desequilibrium. Johansen (1988) develops two statistics; the $\lambda$-max and the trace, to test for the cointegration rank.

\subsection{Model specification and cointegration rank}

The procedure outlined above has been applied to the system including the eight variables described in the last section $\left(Z_{t}=\left[R M_{t}, Y_{t}, \Delta P_{t}, R_{t}, E R_{t}, R_{t}, R_{t}, A_{t}\right]^{\prime}\right)$. However, in empirical applications, the choice of $r$ is frequently sensitive to: $i)$ the deterministic terms included in the system (such as a constant and/or a trend) and on the way in which such components interact with the error correction term; and ii) the appropriate lag length to ensure that the residuals are Gaussian. System (1) is estimated including three lags and an unrestricted constant ${ }^{7}$. Also, two transitory impulse dummies $\left(D_{1}\right.$ and $\left.D_{2}\right)$ have been unrestrictedly (in the short run) introduced ${ }^{8}$ as suggested by Doornik et al. (1998), especially if they are used to establish an estimate of the innovation variance. Multivariate and univariate tests for autocorrelation and normality (Doornik and Hansen, 1994) have been carried out to check for model statistical adequacy before applying the reduced rank tests. Results are shown in Table 1 and indicate that the model can be considered correctly specified.

\section{(Insert Table 1)}

Keeping the lag length at three $(k=3)$, and imposing the hypothesis $H_{r}$, the $\mathrm{I}(1)$ system (1) in error correction form, then, becomes: 


$$
\Delta \mathrm{Z}_{\mathrm{t}}=\sum_{\mathrm{i}=1}^{\mathrm{i}=2} \Gamma_{\mathrm{i}} \Delta \mathrm{Z}_{\mathrm{t}-\mathrm{i}}+\alpha \beta^{\prime} \mathrm{Z}_{\mathrm{t}-1}+\mu+\delta_{1} \mathrm{D}_{1 \mathrm{t}}+\delta_{2} \mathrm{D}_{2 \mathrm{t}}+\varepsilon_{\mathrm{t}}
$$

Table 2 reports the trace and the maximum eigenvalue ( $\lambda$-max) statistics. Both tests indicate that, at the $5 \%$ significance level, it is possible to accept that there are four cointegration vectors ${ }^{9}$. Note that, as some dummy variables have been introduced, results have to be interpreted with some caution. Juselius (1995) suggests, as a first step, looking at the roots of the characteristic polynomial of the VAR model (called companion matrix) since these provide useful information on how many (r-p) roots are on the unit circle. The six first characteristic roots (modulus) are [0.98, 0.96, 0.95,0.93, 0.78, 0.78]. Results show that the four largest values are close to unity, which seems to support the choice of four unit roots in the system (p-r = 4) and it is consistent with the existence of four cointegration vectors. On the other hand, as it can be observed, all the roots are inside the unit circle which confirms that all variables are I(1).

(Insert Table 2)

The estimated $\beta$ parameters are presented in Table 3 , where $\beta$ is presented in normalized form. Identifying economically interpretable relations is the primary aim of this analysis. However, Juselius (1994: 171) argues that "the interpretation of the unrestricted cointegration space is far from straightforward when there are more than one cointegrating vector". Moreover, Johansen and Juselius (1994) suggest that only sometimes the unrestricted cointegrating vectors, surprisingly, can be directly interpreted in terms of theoretical economic relationships. Thus, some restrictions are needed in order to obtain a structural representation of such relationships.

(Insert Table 3)

\subsection{Hypotheses testing on cointegration vectors}

Taking into account the variables included in the model as well as the economic theory which relates those variables, the following hypothetical cointegration relations could be expected: 
1) Real money demand: $\left(\beta^{1}\right)^{\prime} Z_{t}: R M_{t}=\beta_{y}^{1} Y_{t}+\beta_{r}^{1} R_{t}+\beta_{\Delta p}^{1} \Delta P_{t}+\mu^{1}+\varepsilon_{1 t}$

By setting $\beta_{y}^{1}=1$, the previous equation becomes:

$$
\left(\beta^{1}\right)^{\prime} Z_{t}: R M_{t}-Y_{t}=\beta_{r}^{1} R_{t}+\beta_{\Delta p}^{1} \Delta P_{t}+\mu^{1}+\varepsilon_{1 t}
$$

which represents a real demand equation postulated by the quantitative money theory. This equation describes a real money demand under the condition that $\beta_{r}^{1}<0$ and $\beta_{\Delta p}^{1}<0$.

2) The second relationship can be identified as an output demand equation:

$$
\left(\beta^{2}\right)^{\prime} Z_{t}: Y_{t}=\beta_{r}^{2} R_{t}+\beta_{\Delta p}^{2} \Delta P_{t}+\mu^{2}+\varepsilon_{2 t}
$$

The economic theory predicts that in such relationships the real aggregate income is negatively related to the interest rate and positively to inflation $\left(\beta_{\mathrm{r}}^{2}<0\right.$ and $\left.\beta_{\Delta \mathrm{p}}^{2}>0\right)$. However, if $\beta_{\mathrm{r}}^{2}=0$ and $\beta_{\Delta \mathrm{p}}^{2}>0$ this will be consistent with what is called a short-run Phillips curve relationship with growing expectations.

3) The third relationship will attempt to relate agricultural prices

$\left(\beta^{3}\right)^{\prime} \mathrm{Z}_{\mathrm{t}}: \beta_{\text {rop }}^{3} \mathrm{ROP}_{\mathrm{t}}+\beta_{\text {rip }}^{3} \mathrm{RIP}_{\mathrm{t}}+\mu^{3}=\varepsilon_{3 \mathrm{t}} \sim \mathrm{I}(0)$

In this equation, the agricultural prices homogeneity is given by $\beta_{\text {rop }}^{3}+\beta_{\text {rip }}^{3}=0$.

4) The final relationship is going to be associated with an agricultural export equation:

$$
\left(\beta^{4}\right)^{\prime} \mathrm{Z}_{\mathrm{t}}: \mathrm{AX}_{\mathrm{t}}-\beta_{\mathrm{er}}^{4} \mathrm{ER}_{\mathrm{t}}-\beta_{\text {rop }}^{4} \mathrm{ROP}_{\mathrm{t}}+\mu^{4}=\varepsilon_{4 \mathrm{t}} \sim \mathrm{I}(0)
$$

In this equation, it would be expected that $\beta_{\mathrm{er}}^{4}>0$ and $\beta_{\text {rop }}^{4}>0$.

The four long-run relationships given in (4)-(7), can be written more compactly as: 


$$
\beta^{\prime} \mathrm{Z}_{\mathrm{t}-1}=\varepsilon_{\mathrm{t}} \sim \mathrm{I}(0)
$$

where

$$
\beta^{\prime}=\left[\begin{array}{rrrrrrrr}
1 & -1 & * & * & 0 & 0 & 0 & 0 \\
0 & 1 & * & * & 0 & 0 & 0 & 0 \\
0 & 0 & 0 & 0 & 0 & 1 & -1 & 0 \\
0 & 0 & 0 & 0 & * & * & 0 & 1
\end{array}\right]
$$

In this paper, a two-step procedure is going to be used in order to check if (8) is supported by data. In the first step, each single restricted relation (4)-(7) is tested for stationarity leaving the other relations unrestricted. In other words, if restrictions imposed are compatible with a stationary relationship. The second step involves jointly considering the full identification of the four relationships. Juselius (1998) points out that this approach maximizes the chance of finding a correct full identification of long-run relations.

Hypotheses related to the first step adopt the general form $\mathcal{H}_{\mathrm{i}}: \beta=\left(\mathrm{H}_{\mathrm{i}} \varphi, \omega\right)^{10}$. In such an expression, restrictions to be tested are only placed in a single cointegration vector while the remaining (r-1) vectors are considered unrestricted. Johansen and Juselius (1992) suggest that this test can be used when we wish to test if there exists some vector in the cointegration space that linearly combines the variables in a particular hypothesized stationary relationship.

Several hypotheses have been considered and tested. The specification of such hypotheses as well as results found are shown in Table 4. With respect to the first relationship, two different hypotheses have been tested. In the first one $\left(\mathscr{H}_{1}\right)$, it is tested that real money is cointegrated with interest rate and inflation, imposing also income homogeneity. Results from the Likelihood Ratio (LR) statistic indicate that the null cannot be rejected. Both the interest rate and inflation have the expected negative signs. In the second hypothesis, an additional restriction is considered $\left(\beta_{\Delta \mathrm{p}}^{1}=0\right)$. This hypothesis is strongly rejected, which means that the monetary authority is not fixing the monetary policy taking into account an aggregate money stock. This is consistent with the situation in Spain, at least since 1989 when Spain joined the European Monetary System (EMS).

(Insert Table 4) 
The $\mathscr{H}_{3}$ and $\mathscr{H}_{4}$ hypotheses are related to the real income equation specification. As can be observed in Table 4, there is no empirical evidence of a stationary relation between real income and inflation $\left(\mathscr{H}_{4}\right)$. However, the hypothesis that real income, interest rate and inflation form a stationary relation $\left(\mathcal{H}_{3}\right)$ cannot be rejected. This means that, as real output is negatively related to interest rate and positively to inflation, this equation can be interpreted as an excess demand for goods relationship.

Hypothesis $\left(\mathscr{H}_{5}\right)$ tests for price homogeneity in the agricultural sector. The LR statistic is under the critical value suggesting that monetary policy has a neutral effect on the real food-based prices. This means that, in the long run, input prices and output prices react in the same way and magnitude to changes in money supply. The last hypothesis $\left(\mathcal{H}_{6}\right)$ tests that real agricultural exports, exchange rate and output prices form a stationary relationship. Again, the null hypothesis cannot be rejected at 5\% significance level and additionally, variables have the expected signs.

Once it has been checked that each single equation is a cointegrated relationship, the second step consists of testing a full identification of the structural long-run relationships. Following Johansen and Juselius (1994), the $\mathscr{H}_{1}, \mathcal{H}_{3}, \mathscr{H}_{5}$ and $\mathscr{H}_{6}$ hypotheses can be jointly tested (see expression 8) using the general hypothesis $\mathcal{H}_{\beta}: \beta=\left(\mathrm{H}_{1} \varphi_{1}, \mathrm{H}_{2} \varphi_{2}, \mathrm{H}_{3} \varphi_{3}, \mathrm{H}_{4} \varphi_{4}\right)^{11}$. As the total number of restrictions is 22 , the system is over-identified. The LR statistic is 15.84 , which is well under the critical value at the $5 \%$ level of significance $\left(\chi^{2}(10)=18.30\right)$. Then, the null hypothesis cannot be rejected and the imposed restrictions have empirical support. The new estimated $\beta$ matrix is shown in Table 5 . Thus, the estimated long-run relations (zero-mean I(0) linear combinations) incorporating all restrictions and the unrestricted constant are:

$$
\begin{aligned}
& \mathrm{RM}_{t}-\mathrm{Y}_{\mathrm{t}}=-15.078 \Delta \mathrm{P}_{\mathrm{t}}-0.452 \mathrm{R}_{\mathrm{t}}-2.437+\varepsilon_{1 \mathrm{t}} \\
& \mathrm{Y}_{\mathrm{t}}=9.219 \Delta \mathrm{P}_{\mathrm{t}}-0.321 \mathrm{R}_{\mathrm{t}}+9.806+\varepsilon_{2 \mathrm{t}} \\
& \mathrm{ROP}_{\mathrm{t}}=\mathrm{RIP}_{\mathrm{t}}+0.299+\varepsilon_{3 \mathrm{t}} \\
& \mathrm{AX}_{\mathrm{t}}=-0.934 \mathrm{ER}_{\mathrm{t}}-0.891 \mathrm{ROP}_{\mathrm{t}}+4.271+\varepsilon_{4 \mathrm{t}}
\end{aligned}
$$


All coefficients are statistically significant and have the expected theoretical signs. However, Juselius (1999: 264) points out that "it is no longer possible to interpret a coefficient in a cointegrating relation as in conventional regression context....In multivariate cointegration analysis all variables are stochastic and a shock to one variable is transmitted to all variables via dynamics of the system until the system has found its new equilibrium position"12.

On the other hand, in this type of analysis it is also convenient to consider the $\alpha$ matrix parameters as they provide a valuable information about the speed of adjustment of each variable to the long-run equilibrium. Juselius (1994: 169) suggests that " the interpretation of a cointegration relation $\left(\beta^{\mathrm{i}}\right)^{\prime} \mathrm{Z}_{\mathrm{t}-1}$ as a potentially interesting economic relation cannot be done without jointly considering the estimates of $\alpha_{i j}$ " (i indicates the row and $j$ the column). The estimated alpha coefficients are also shown in Table 5 as well as their respective t-values ${ }^{13}$. As the relationships between macroeconomic variables and the agricultural sector are of interest for this study, let us focus on such relationships. The first interesting result is that, in general terms, adjustment coefficients of macroeconomic variables to changes in the agricultural long-run relationships $\left(\alpha_{13}, \alpha_{14}, \alpha_{23}, \alpha_{24}, \alpha_{34}, \alpha_{43}, \alpha_{44}\right.$, and $\left.\alpha_{53}\right)$ are not significant. The only exception is that it seems that inflation responds to changes in the agricultural prices relationship $\left(\alpha_{33} \neq 0\right)$.

As far as the price transmission mechanism is concerned, it has already been pointed out that in the long run, price neutrality holds, that is, input and output prices respond proportionally to changes in money supply in the long run. However, the situation in the short-run is somewhat different. It seems that producer prices react quicker than input prices to unanticipated shocks in the long-run equilibrium relationships. This question can be analysed from three different points of view. First, by considering producer and input prices deviations from such neutrality relationship in the short run (the third cointegrating vector). Deviations are measured by $\alpha_{63}$ and $\alpha_{73}$ parameters, respectively. As it can be observed, at the $5 \%$ level of significance, the hypotheses that $\alpha_{63}=0$ and $\alpha_{73}>0$ cannot be rejected, implying that agricultural output prices are weakly exogenous with respect to the long-run agricultural prices equilibrium. This result would indicate that there exists evidence in favour of a demand-pull price transmission mechanism, as a shock in this price would induce short-run 
adjustments in input prices but not the opposite. In other words, the output price is the common stochastic trend that drives the agricultural variables.

In addition, according to the real output equation (second cointegrating vector), inflation increases with excess aggregate demand. The question whether output prices cause input prices (demand-pull transmission) or input prices cause output prices (cost-push) can also be tested taking into account the magnitude and sign of $\alpha_{62}$ and $\alpha_{72}$ parameters. Results from Table 5 indicate that $\alpha_{62}>0$ and $\alpha_{72}=0$. Thus, inflation from excess demand produces changes in the demand for farm products and elicits, in turn, changes in output prices which will be transmitted to input prices in a way that leaves neutrality in the long run.

Finally, the question of price transmission in the short-run can be analysed by taking into account input and output prices reactions to deviations from a stable money-demand relation (first cointegrating vector), that is, looking at $\alpha_{61}$ and $\alpha_{71}$ coefficients. As it is shown in Table 5, $\alpha_{61}>\alpha_{71}$, indicating that the magnitude of adjustment to long-run money demand equilibrium is higher in the case of output prices. The three results mentioned above seem to reinforce the idea of a demand-pull transmission mechanism in the agricultural sector. However, the simple consideration of the magnitude of adjustments to long-run relationships is not enough. The analysis has to be complemented with an indication of the reaction time path. The impulse response functions provide such answer and they will be analysed in the next $\operatorname{section}^{14}$.

\section{SHORT-RUN DYNAMICS}

In order to analyse the dynamic responses of agricultural variables to macroeconomic shocks, impulse response functions have been computed. Generally, the dynamic analysis from VAR models is carried out using the Cholesky decomposition. However, functions generated from such an approach, in many cases, are difficult to be economically interpreted, as their innovations are not identified with the underlying structural error. To overcome this problem, in this paper a structural VAR in error-correction form (SVECM) has been considered. The SVECM can be obtained by premultiplying the reduced form of the VECM 
used in the I(1) analysis (equation 7 with all non-rejected restrictions on $\alpha$ and $\beta$ imposed) by a (pxp) $A_{0}$ matrix. The model, then, becomes:

$$
\mathrm{A}_{0} \Delta \mathrm{Z}_{\mathrm{t}}=\sum_{\mathrm{i}=1}^{\mathrm{i}=2} \mathrm{~A}_{\mathrm{i}} \Delta \mathrm{Z}_{\mathrm{t}-\mathrm{i}}+\mathrm{a}_{\alpha}\left(\hat{\beta}^{\prime} \mathrm{Z}_{\mathrm{t}-1}\right)+\eta+\lambda_{1} \mathrm{D}_{1 \mathrm{t}}+\lambda_{2} \mathrm{D}_{2 \mathrm{t}}+\mathrm{u}_{\mathrm{t}}
$$

where $\mathrm{u}_{\mathrm{t}} \sim \operatorname{iid}(0, \Omega) ; \mathrm{A}_{\mathrm{i}}=\mathrm{A}_{0} \Gamma_{\mathrm{i}}, \mathrm{a}_{\alpha}=\mathrm{A}_{0} \alpha ; \eta=\mathrm{A}_{0} \mu ; \lambda_{1}=\mathrm{A}_{0} \delta_{1}$ and $\lambda_{2}=\mathrm{A}_{0} \delta_{2} ; \mathrm{u}_{\mathrm{t}}=\mathrm{A}_{0} \varepsilon_{\mathrm{t}} ; \Omega=\left(\mathrm{A}_{0}\right) \Sigma\left(\mathrm{A}_{0}\right)^{\prime}$; and $\beta$ has been already defined in Table 5 .

The $\mathrm{A}_{0}$ coefficients contain the contemporaneous linkages between all the endogenous variables in $\mathrm{Z}_{\mathrm{t}}$.

Following Amisano and Giannini (1997), and previous to computing the impulse response functions, system (10) has to be identified, that is, at least $\mathrm{p} \times(\mathrm{p}-1) / 2$ restrictions must be imposed in the $A_{0}$ matrix. These restrictions have to be based on economic theory and are of exclusion type, implying that certain variables are excluded from the relationships. The identification process requires also that the $A_{0}$ matrix has unity values in the main diagonal after normalization.

Several short-run identifications have been considered taking into account the following three main assumptions. First, it is assumed that macroeconomic variables do not respond contemporaneously to innovations in the agricultural variables. Second, inflation has been considered completely predetermined for the current period, assuming that it is the common stochastic trend driving macroeconomic variables. Finally, it has been considered that among macroeconomic variables, only interest rate and exchange rate contemporaneously affect agricultural variables.

In Table 6 (left hand), the identified $\mathrm{A}_{0}$ matrix is shown. The first equation is specified as a money demand relationship depending on interest rate and inflation. The second one is identified as a real aggregate demand where interest rate and inflation are considered as explanatory variables. As mentioned before, inflation is considered predetermined (third equation). Interest rate is expressed as a function of inflation (forth equation). The exchange rate equation is the fifth one including income and interest rate as main determinants. The last three 
equations are related to the agricultural variables. Output price is defined as a function of input price and exchange rate while input price is expressed as a function of exchange rate and interest rate. Finally, agricultural exports are assumed to depend on exchange rate and output price. The final model has been estimated using the Maximum Likelihood (FIML) procedure ${ }^{15}$. The likelihood ratio statistic of the over-identifying restrictions is 17.31 , which is under the critical value of a $\chi^{2}(15)$ at the $5 \%$ level (25.00). Thus, the imposed restrictions seem to be consistent with theoretical considerations and are supported by data. The estimated $\mathrm{A}_{0}$ matrix is shown in Table 6 (right hand). As it can be observed all relationships are economically meaningful since signs are as expected. The most interesting result is that in the interest rate equation the inflation coefficient is of opposite sign with respect to the interest rate.

(Insert Table 6)

Elements in vector $\mathrm{u}_{\mathrm{t}}$ in (10) are the innovations to $\Delta \mathrm{Z}_{\mathrm{t}}$. Then, the impulse responses of $\Delta \mathrm{Z}_{\mathrm{t}}$ to shocks can be computed from the moving-average representation of $\Delta \mathrm{Z}_{\mathrm{t}}$ in terms of $\mathrm{u}_{\mathrm{t}}$ However, it is often more convenient to interpret changes in the level of $\mathrm{Z}_{\mathrm{t}}$ in response to different shocks (Lütkepohl and Reimers, 1992 and Gonzalo and Ng, 1996). This can be easily constructed by reparametrising the VECM (2) to its equivalent formulation in levels and then obtaining its moving average representation. For each response, the standard deviation is computed using Lütkepohl's (1993) procedure. As 64-impulse response functions are obtained, Figure 2 only shows estimated impulse responses of agricultural variables to a shock in the main variables in the system, together with their two standard error bands.

\section{(Insert Figure 1)}

A shock in the real quantity of money generates higher interest rates and the exchange rate is appreciated (not shown in Figure 1), which is consistent with prior beliefs that a tight money shock leads to an appreciation of the domestic currency. As a consequence, agricultural exports decrease. On the other hand, input and output prices reactions are very small in the very short-run. A positive shock in the real quantity of money (through an unexpected increase in the nominal quantity of money) leads to an increase in demand as long as the monetary shock does not lead to rising inflation. Later, when the real quantity on 
money is back on the original level also the real prices of the agricultural goods are not significantly different from their original level. ${ }^{16}$

As can be seen in Figure 1, a positive inflation shock increases immediately both input and output prices and reduces agricultural exports. However, it seems that over longer horizons the terms of trade for the agricultural sector get worse. In fact, the impulse response function shows that the real output price is not significantly different from the original level while the real input price remains on a significantly higher level.

A shock in the exchange rate (which means appreciation taking into account how exchange rate has been defined) generates an immediate negative reaction of agricultural exports. There exists an over-reaction after five quarters and the initial shock has quite a permanent effect. Decreasing exports generate an increasing share of agricultural production sold within the country, pushing input and output prices down. In the very short-run producer prices reactions are almost null, which can be explained by the existence of the green exchange rate which was established to mitigate consequences of market exchange variations.

Let us concentrate now on the reaction of agricultural variables to a shock in the interest rate. The nominal interest rate goes up inducing a moderate but significant currency appreciation (not shown in Figure 1). As a consequence, the shock has a negative effect on agricultural exports but lower in magnitude with respect to exchange rate changes. Input and output prices react positively. However, as in the case of a shock in inflation, the real input price remains significantly above its original level over longer horizons than in the case of the real output price.

Shocks in agricultural innovations do not generate any effect on macroeconomic variables and, then, they are not shown in Figure 1. A shock in the producer price leads to an immediate decrease of agricultural exports. Input price increases significantly after fivequarters. In the long run neutrality holds. Finally, output prices response quickly to a shock in the price of inputs used in agriculture. However, in this case, neutrality is reached sooner.

\section{CONCLUDING REMARKS}

The objective of this paper is to apply recent developments in the econometric analysis of time series to the study of relationships between macroeconomic variables and the 
agricultural sector in Spain. Results from this study suggest a number of points. The first one is that it is interesting to distinguish between long-run and short-run analyses. Long-run analysis is usually associated with structural relationships and it is in this context where theoretical restrictions have to be tested. Short-run analysis is also important for policy analysis as it gives an idea of the magnitude and time path reactions of economic variables to deviations from long-run relationships. However, the variables' short-run responses to shocks have to be calculated with the aid of theoretically based long-run economic restrictions.

Results from the long-run analysis indicate that most of the theoretical relationships among macroeconomic and agricultural variables hold. The real quantity of money is neutral with respect to aggregate income. It has also been found that in the long run agricultural prices are homogeneous, that is, input and output prices reactions are of the same magnitude. It is also noticeable that, in the long run, changes in agricultural variables have not a significant impact on macroeconomic variables. The only exception is the effect of agricultural prices on inflation, a question which has arisen some controversy in last years in Spain. Finally, taking into account the speed of adjustment coefficients, there exists an empirical evidence of a demand-pull transmission mechanism between agricultural input and output prices.

The analysis of short-run dynamics has also provided some useful information. In spite of agricultural prices are homogeneous in the long run, output prices seems to be more flexible in the very short run and react quicker than input prices. However, over longer time horizons output prices are not significantly different from their original level while input prices remain on a significantly higher level. This would indicate that the terms of trade for the agricultural sector would get worse. Also, in the very short-run, agricultural exports are more sensitive to agricultural prices than to any other macroeconomic variable.

The current trend of lower interest rates in Spain has important effects on the foreign competitiveness of the Spanish agricultural sector. On the other hand, inflation is under control so it is expected that in the future the main determinants of the competitiveness of the agricultural sector will be domestic prices and interest rate. To conclude, it has to be said that results presented in this paper depend on the variables and sample period chosen. Further analysis, including other variables and extended sample period, could be conducted in the future. 
Table 7. Misspecification tests in the system

\begin{tabular}{|c|c|c|c|c|c|c|c|c|}
\hline & $\mathrm{RM}_{\mathrm{t}}$ & $\Delta \mathrm{P}_{\mathrm{t}}$ & $Y_{t}$ & $\mathrm{R}_{\mathrm{t}}$ & $\mathrm{ER}_{\mathrm{t}}$ & $\mathrm{ROP}_{\mathrm{t}}$ & $\mathrm{RIP}_{\mathrm{t}}$ & $\mathrm{AX}_{\mathrm{t}}$ \\
\hline & \multicolumn{8}{|c|}{ Univariate tests } \\
\hline $\operatorname{AR}(1)^{\mathrm{a}} \sim \chi^{2}(1)=3.84$ & 1.83 & 3.15 & 1.09 & 2.51 & 0.81 & 0.43 & 2.28 & 0.25 \\
\hline $\operatorname{AR}(4)^{\mathrm{a}} \sim \chi^{2}(1)=3.84$ & 0.66 & 3.17 & 3.01 & 0.23 & 3.10 & 1.59 & 2.44 & 0.55 \\
\hline \multirow[t]{2}{*}{$\mathrm{JB}^{\mathrm{b}} \sim \chi^{2}(2)=5.99$} & 0.51 & 6.22 & 2.08 & 0.25 & 2.42 & 3.57 & 3.85 & 0.24 \\
\hline & \multicolumn{8}{|c|}{ Multivariate tests } \\
\hline \multirow[t]{2}{*}{ Autocorrelation test $^{\mathrm{C}}$} & \multicolumn{2}{|c|}{$\mathrm{LM}(1)=$} & 69.38 & $\sim \quad \chi$ & $\chi^{2}(64)=$ & \multicolumn{3}{|l|}{83.58} \\
\hline & \multicolumn{2}{|c|}{$\operatorname{LM}(4)=$} & 75.02 & $\sim$ & $\chi^{2}(64)=$ & \multicolumn{3}{|l|}{83.58} \\
\hline Normality & \multicolumn{2}{|c|}{$\operatorname{Nor}^{\mathrm{d}}=$} & 21.41 & $\sim$ & $\chi^{2}(16)=$ & \multicolumn{3}{|l|}{26.30} \\
\hline
\end{tabular}

a. AR (i) is the Breusch-Godfrey test for autocorrelation of $i^{\text {th }}$ order .

b. JB is the univariate Jarque-Bera test of normality.

c. $L M(i)$ is the Godfrey multivariate test for autocorrelation of $i^{\text {th }}$ order.

d. Nor is the Doornik and Hansen (1994) multivariate test for normality.

Table 8. Results from multivariate contegration tests

\begin{tabular}{|c|c|c|c|c|c|c|c|}
\hline $\mathrm{H}_{0}{ }^{\mathrm{a}}$ : & $\mathrm{p}-\mathrm{r}$ & Trace & $\lambda$-max & $\begin{array}{r}\text { CV(90\%) } \\
\text { Trace }^{\mathrm{b}}\end{array}$ & $\begin{array}{r}\text { CV(95\%) } \\
\text { Trace }^{b}\end{array}$ & $\begin{array}{r}\mathrm{CV}(90 \%) \\
\lambda-\mathrm{max}^{\mathrm{b}}\end{array}$ & $\begin{array}{r}\mathrm{CV}(95 \%) \\
\lambda-\max ^{\mathrm{b}}\end{array}$ \\
\hline $\mathrm{r}=0$ & 8 & 268.42 & 81.16 & 150.53 & 156.00 & 48.33 & 51.42 \\
\hline $\mathrm{r} \leq 1$ & 7 & 187.27 & 60.00 & 111.50 & 124.24 & 42.32 & 45.28 \\
\hline$r \leq 2$ & 6 & 127.27 & 45.15 & 89.48 & 94.15 & 36.76 & 39.37 \\
\hline$r \leq 3$ & 5 & 82.11 & 38.38 & 64.84 & 68.52 & 30.90 & 33.46 \\
\hline $\mathrm{r} \leq 4$ & 4 & 43.73 & 19.35 & 43.95 & 47.21 & 24.73 & 27.07 \\
\hline$r \leq 5$ & 3 & 24.38 & 16.88 & 26.79 & 23.68 & 18.60 & 20.97 \\
\hline$r \leq 6$ & 2 & 7.50 & 7.34 & 13.33 & 15.41 & 12.07 & 14.07 \\
\hline $\mathrm{r} \leq 7$ & 1 & 0.16 & 0.16 & 2.69 & 3.76 & 2.69 & 3.76 \\
\hline
\end{tabular}

$a$.the null hipótesis of the trace statistic is $r r_{0}$ against the unrestricted alternative. In the $\lambda$-max statistic the null is $r=r_{0}$ agaist the alternative $r=r_{0}+1$.

b critical values are obtained from Osterwald-Lenum (1992). 
Table 9. Estimated parameters of $\beta$ matrix with $r=4$

\begin{tabular}{lrrrr}
\hline & \multicolumn{3}{c}{$\beta^{\mathrm{i}}$} & \\
\hline & Vector_1 & Vector_2 & Vector_3 & Vector_4 \\
\hline $\mathrm{RM}_{\mathrm{t}}$ & 1.000 & -0.217 & -0.834 & 0.036 \\
$\mathrm{Y}_{\mathrm{t}}$ & -1.201 & -0.037 & -7.162 & -0.544 \\
$\Delta \mathrm{P}_{\mathrm{t}}$ & 13.089 & 1.000 & 0.242 & 5.071 \\
$\mathrm{R}_{\mathrm{t}}$ & 0.368 & 0.006 & -0.471 & -7.236 \\
$\mathrm{ER}_{\mathrm{t}}$ & -0.178 & 0.013 & 1.312 & 1.581 \\
$\mathrm{RIP}_{\mathrm{t}}$ & -0.455 & 0.56 & -0.892 & 0.566 \\
$\mathrm{ROP}_{\mathrm{t}}$ & 0.155 & -0.091 & 1.000 & 0.871 \\
$\mathrm{AX}_{\mathrm{t}}$ & 0.205 & 0.035 & 0.483 & 1.000 \\
\hline
\end{tabular}

Table 10. Hypothesis restrictions tests on the cointegration vectors ${ }^{\mathrm{a}, \mathrm{b}}$

\begin{tabular}{|c|c|c|c|}
\hline $\begin{array}{l}\text { Null hypothesis: } \\
\mathscr{H}_{\mathrm{i}}: \beta=\left(\mathrm{H}_{\mathrm{i}} \varphi, \psi\right)\end{array}$ & Restrictions & LR test & Critical Value (5\%) \\
\hline $\mathscr{H}_{1}$ & $\mathrm{H}_{1}=\left[\begin{array}{llllllll}1, & -1, & * & * & 0, & 0, & 0, & 0\end{array}\right]$ & 1.28 & $\sim \chi^{2}(2)=5.99$ \\
\hline $\mathscr{H}_{2}$ & $\mathrm{H}_{2}=\left[\begin{array}{llllllll}1, & -1, & 0, & * & 0, & 0, & 0, & 0\end{array}\right]$ & 9.88 & $\sim \chi^{2}(3)=7.81$ \\
\hline $\mathscr{H}_{3}$ & $\mathrm{H}_{3}=[0,1, * *, *, 0,0,0,0]$ & 3.64 & $\sim \chi^{2}(2)=5.99$ \\
\hline $\mathscr{H}_{4}$ & $\mathrm{H}_{4}=[0,1, *, 0,0,0,0,0]$, & 8.98 & $\sim \chi^{2}(3)=7.81$ \\
\hline $\mathscr{H}_{5}$ & $\mathrm{H}_{5}=\left[\begin{array}{llllllll}0, & 0, & 0, & 0, & 0, & 1, & -1, & 0\end{array}\right]$ & 5.58 & $\sim \chi^{2}(4)=9.49$ \\
\hline $\mathscr{H}_{6}$ & $\mathrm{H}_{6}=\left[\begin{array}{lllllll}0, & 0, & 0, & 0, & * & * & 0,1\end{array}\right]$ & 2.29 & $\sim \chi^{2}(2)=5.99$ \\
\hline
\end{tabular}

a . An * indicates that the coefficient is unrestricted.

b. The degrees of freedom are calculated as follows: $r_{1}\left(p-m_{1}-r_{2}\right)$, where $r_{1}$ is the number of restricted cointegration vectors (in our case $r_{1}=1$ ), $r_{2}$ is the number of unrestricted cointegration vectors and $m_{1}$ is the number of estimated parameters within the $r_{1}$ vectors 
Table 11. Estimated $\beta$ and $\alpha$ matrices under long-run identification

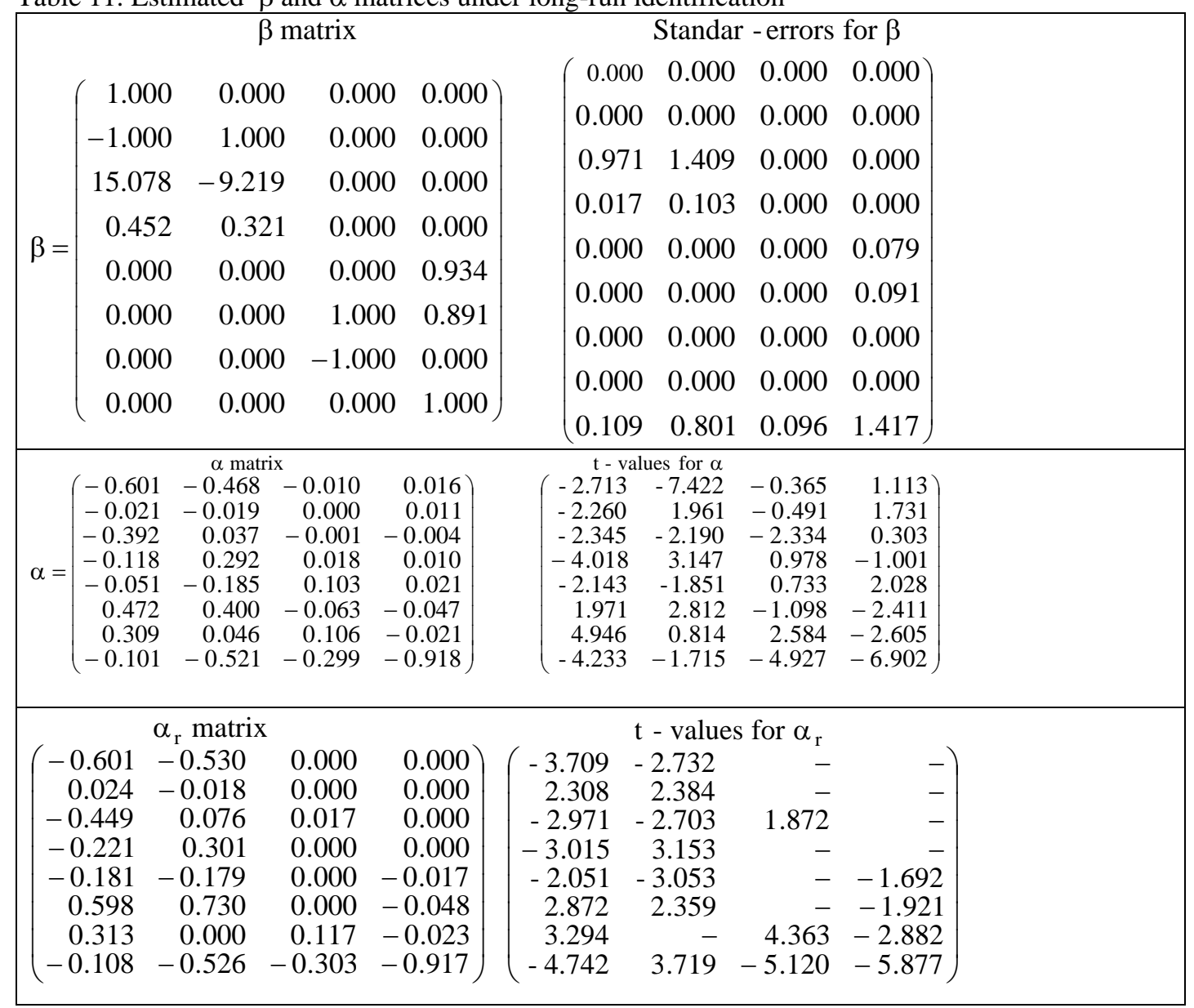

Table 12. Contemporaneous specification and estimated coefficients of the SVECM ${ }^{\mathrm{a}}$

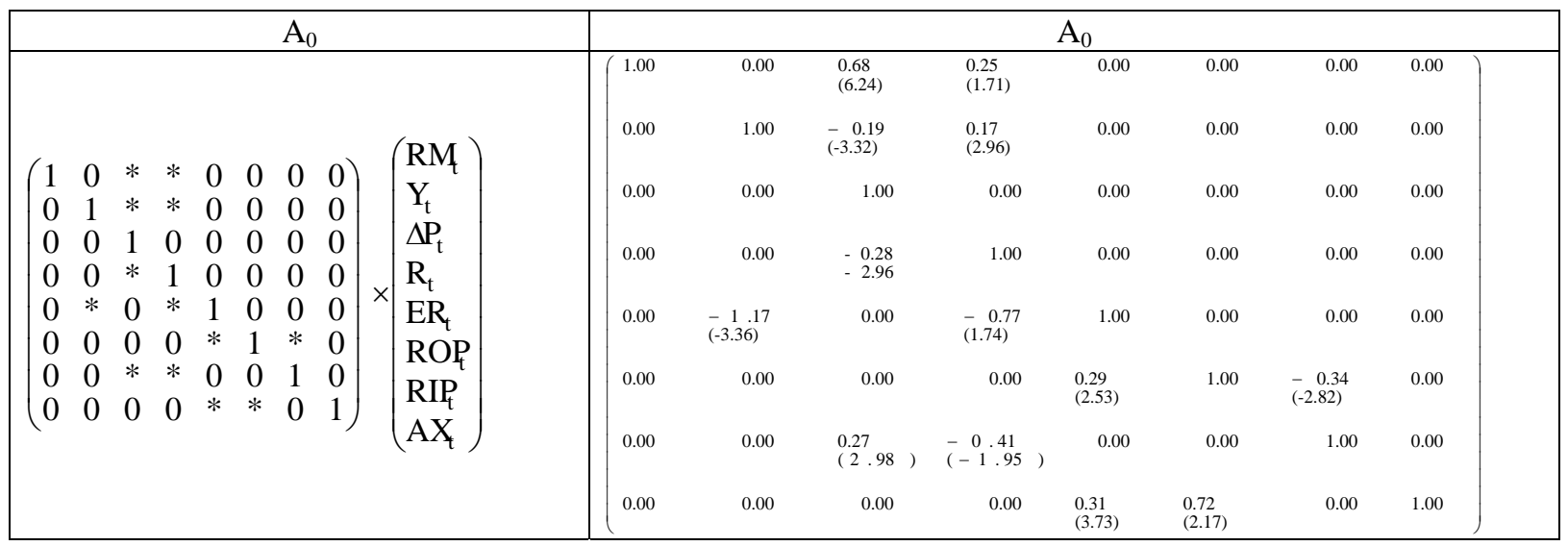

a: Values in parentheses are t-values. 
Figure 1. Responses of agricultural variables to one-standard-deviation shock from SVECM ${ }^{\mathrm{a}}$

Shock in Money Demand
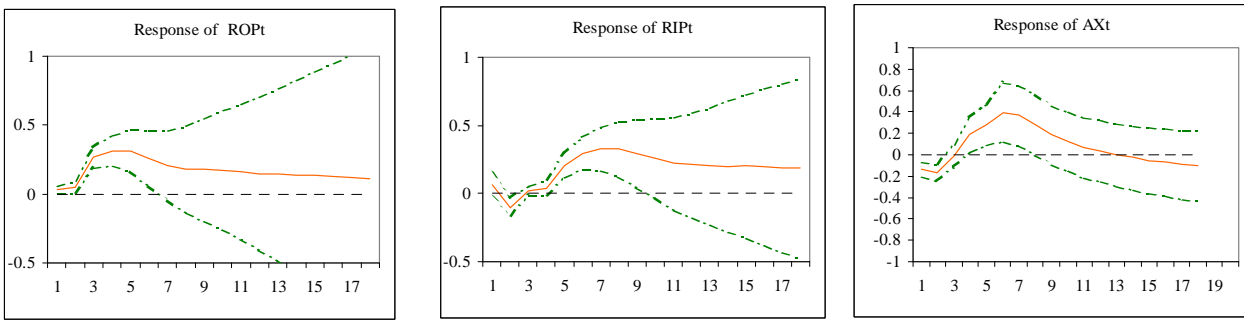

Shock in inflation
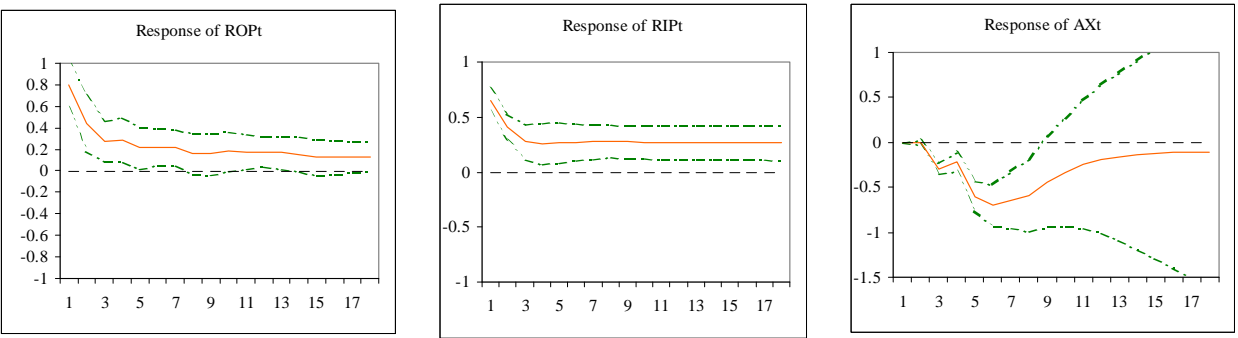

Shock in interest rate
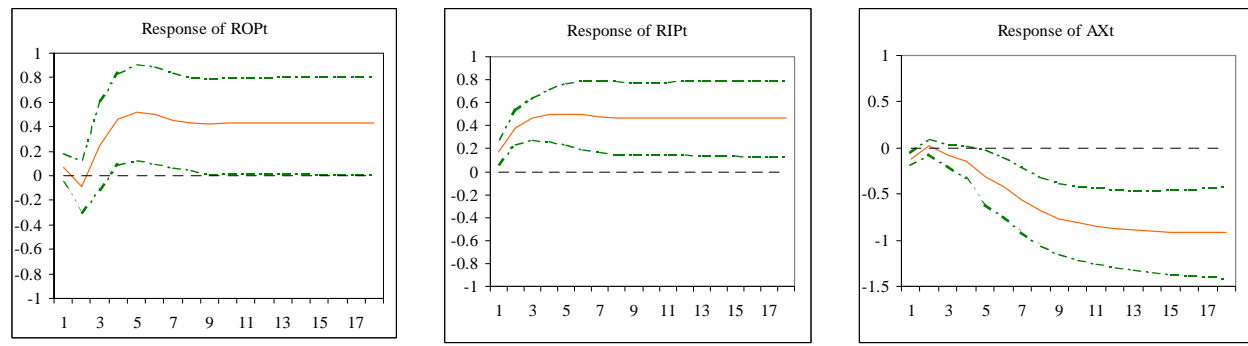

Shock in exchange rate
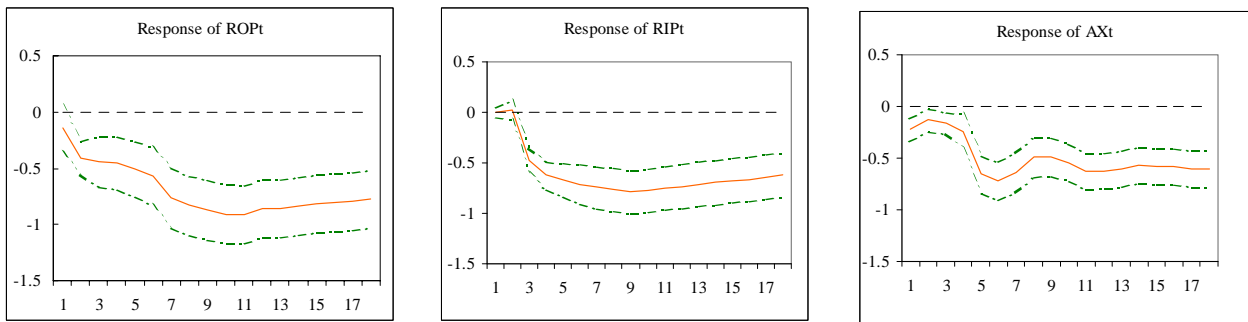

Shck in input price
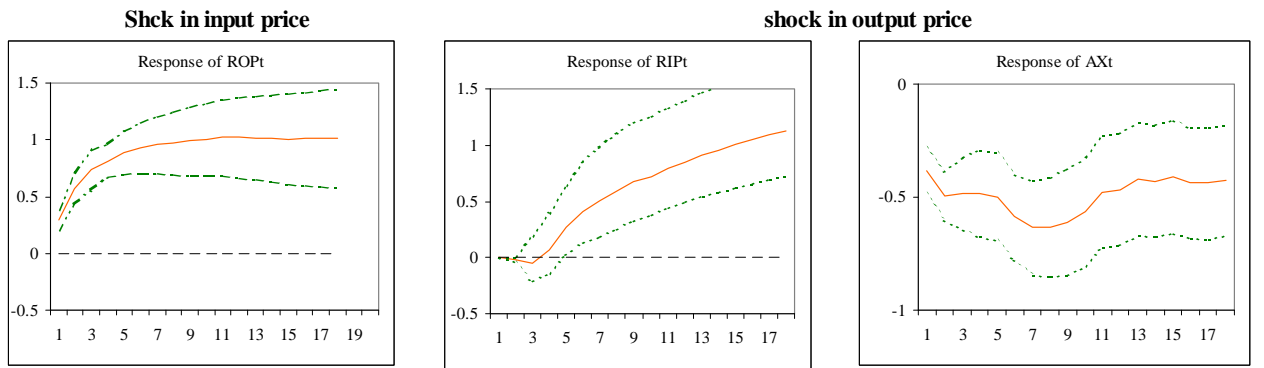

a. Confidence bands are calculated at the $5 \%$ level of significance 


\section{Notes}

(1) Recent applications in the European context can be found in Matthews and Hanrahan (1996), for Ireland, and Kuhl and Schmitz (1998), for Germany.

(2) In this paper, exchange rate is defined as the unit value of the Spanish currency in relation to foreign currencies; that is, an increase (decrease) in the exchange rate means appreciation (depreciation) of the Spanish currency (Banco de España, 2000).

(3) The broader definition of money supply has been used, that is, including all liquid assets held by the public.

(4) Data sources are: "Boletin Estadístico del Banco de España” (nominal money supply, ER and R); "Boletines estadísticos del Instituto Nacional de Estadística (INE)” (Y and P); "Boletin Estadístico del Ministerio de Agricultura, Pesca y Alimentación ” (nominal input and output prices); and "Dirección General de Aduanas” (AX).

(5) Seasonal unit root tests were also performed but results indicate that series had seasonal unit roots at different frequencies and, then, seasonal cointegration tests could not be formulated. Filtering each series taking into account its respective seasonal unit roots generate meaningless economic results. Thus, the X11 ARIMA procedure has been used to deseasonalize all series. Although this procedure is subject to limitations as Ghysels and Perron (1993) pointed out, it has been common practice in macro-econometric analyses.

(6) Results are not shown due to space limitations. They are available upon request.

(7) An unrestricted constant in the model gives rise, in general, to a linear trend in the I(1) components and a non zero-mean in the $\mathrm{I}(0)$ components (cointegration vectors).

(8) $\mathrm{D}_{1}$ takes the value 1 over the period 1978:1-1980:4 and zero in other case, while $\mathrm{D}_{2}$ takes the value 1 over the period 1992:1-1992:4. In the first case, we have taken into account the structural change that took place in the agricultural sector which faced higher production costs. In the second, we account for the devaluation process that took place in those years.

(9) All calculations have been performed using the software CATS in RATS (Hansen and Juselius, 1994) and MALCOLM in RATS (Mosconi, 1998).

(10) See Johansen and Juselius (1992) for a full description of the procedure to formulate and test such hypotheses.

(11) A full description of the testing procedure is in Johansen and Juselius (1994) and Johansen (1995).

(12) We are very grateful to a referee who suggested this point to us.

(13) Apart from considering individual significativeness of each $\alpha_{\mathrm{ij}}$ (and taking into account restrictions imposed on the $\beta$ matrix (Table 5), a joint test that all non significative parameters are zero $\left(\alpha_{13}, \alpha_{14}\right.$, $\alpha_{23}, \alpha_{24}, \alpha_{34}, \alpha_{43}, \alpha_{44}, \alpha_{53}, \alpha_{63}$ and $\alpha_{72}$ ) was carried out. A likelihood ratio statistic (Mosconi, 1998) was used to test such hypothesis. Results indicated that the null of no significance could not be rejected (the statistic value, $L R=16.29$, was under the critical value at the $5 \%$ level $\left(\chi^{2}(10)=18.30\right)$. The new restricted $\alpha$ matrix $\left(\alpha_{\mathrm{r}}\right)$ is shown at the bottom of Table 5 .

(14) The Decomposition of the Forecast Error Variance (DFEV) is another useful tool to carry out this kind of analysis as a referee pointed out. Both analyses were carried out and results were quite consistent. Due to space limitations, it has been preferred to include the impulse response analysis only.

(15) The SVAR is estimated using the MALCOLM in RATS software (Mosconi, 1998)

(16) We are very grateful to an anonymous referee for suggesting such interpretation 


\section{References}

Amisano, G. and Giannini, C. (1997). Topics in Structural VAR Econometrics. Springer, New York.

Banco de España (2000). Boletín Estadístico, Enero, Madrid.

Batten, D.S. and Belongia, M.T. (1986). Monetary Policy, Real Exchange Rates and U.S. Agricultural Export. American Journal of Agricultural Economics 68: 422-427.

Bernanke, B.S. (1986). Alternative Explanations of the Money-Income Correlation. Cambridge, MA: National Bureau of Economic Research, Working Paper N ${ }^{\circ} .1842$.

Bessler, D.A. and Babula, R.A. (1987). Forecasting Wheat Export: Do Exchange Rate Matter?. Journal of Business and Economic Statistics 5: 397-406.

Blanchard, O.J. and Quah, D. (1989). The Dynamic Effects of Aggregate Demand and Supply Disturbances. American Economic Review 79: 655-673.

Blough, S.R. (1992). The Relationship between Power and Level for Generic Unit Root Tests in Finite Samples. Journal of Applied Econometrics 7: 295-308.

Bordo, M. D. (1980). The Effects of Monetary Change on Relative Commodity Prices and the Role of Long-Term Contracts. Journal of Political Economy 88: 1088-1109.

Collins, K. J., Meyers, W. H. and Bredahl, M.E. (1980). Multiple Exchange Rate Changes and U.S. Agricultural Commodity prices. American Journal of Agricultural Economics, 62: 656-665.

Cooley, T. G. and LeRoy, S. F. (1985). Atheoretical Macroeconomics: A Critique. Journal of Monetary Economics 16: 283-308.

Chambers, R. G. (1984). Agricultural and Financial Market Interdependence in the Short Run. American Journal of Agricultural Economics 66: 12-24.

Chambers, R. G. and Just, R. E. (1979). A Critique of Exchange Rate Treatment in Agricultural Trade Models. American Journal of Agricultural Economics 61: 249-257.

- (1981). Interrelationships between Money Instruments and Agricultural Commodity Trade. American Journal of Agricultural Economics 63: 934-941.

Denbaly, M. and Torgerson, D. (1991). Macroeconomic Determinants of Relative Wheat Prices: Integrating the Short Run and Long Run. Journal of Agricultural Economics Research 44(2): 2735.

Devadoss, S. and Meyers, W. H. (1987). Relative Prices and Money: Further Results for the United States, American Journal of Agricultural Economics 69:838-842.

Devadoss, S., Meyers, W. H. and Starleaf, D. R. (1987). Macrolinkages between the Farm and no Farm Sectors and the Impact of Monetary Policy Decisions. CARD Monograph 87-M1. Center for Agricultural and Rural Development. IOWA State University.

Dickey, D. A. and Fuller, W. A. (1979). Distribution of Estimators for Autoregressive Time Series with Unit Root. Journal of the American Statistical Association 74: 427-431.

- (1981). Likelihood Ratio Statistics for Autoregressive Time Series with a Unit Root. Econometrica 49: 1057-1072.

Doornik, J. and Hansen, H. (1994). A Practical Test for Univariate and Multivariate Normality. Discussion paper, Nuffield College, Oxford.

Doornik, J. A., Hendry, D. F. and Nielsen, B. (1998). Inference in Cointegrating Models: UK M1 Revisited. Journal of Economic Surveys 12(5): 533-572.

Dorfman, J. H. and Lastrapes, W. D. (1996). The Dynamic Responses of Crop and Livestock Prices to Money-Supply Shock: A Bayesian Analysis Using Long-Run Identifying Restrictions. American Journal of Agricultural Economics 78: 530-441.

Ghysels, E. and Perron, P. (1993). The Effect of Seasonal Adjustment Filters on Tests for a Unit Root. Journal of Econometrics 55: 57-98.

Gonzalo, J. and Ng, S. (1996). A Systematic Framework for Analyzing the Dynamic Effects of Permanent and Transitory Shocks, Working Paper $N^{o}$ 96-16. Departamento de Estadística y Econometría. Universidad Carlos III de Madrid.

Hansen, H. and Juselius, K. (1994). CATS in RATS, Manual to Cointegration Analysis of Time Series, Estima, Institute of Economics, University of Copenhagen. 
In, F. and Mount, T. (1994). Dynamic Macroeconomic Linkages to the Agricultural Sector. Athenaeum Press Ltd, Newcastle upon Tyne.

Johansen, S. (1988). Statistics Analysis of Cointegration Vectors. Journal of Economic Dynamics and Control 12: 231-254.

-(1995). Identifying Restrictions of Linear Equations with Applications to Simultaneous Equations and Cointegration. Journal of Econometrics 69:111-132.

Johansen, S. and Juselius, K. (1990). Maximum Likelihood Estimation and Inference on Cointegrationwith Applications to the Demand for Money. Oxford Bulletin of Economics and Statistics 52: 169-210.

- (1992). Testing Structural Hypotheses in a Multivariate Cointegration Analysis of the PPP and the UIP for UK. Journal of Econometrics 53: 211-244.

- (1994). Identification of the Long-Run and the Short-Run Structure: An Application to the ISLM Model. Journal of Econometrics 63: 7-36.

Juselius, K. (1994). On the Duality between Long-Run Relations and Common Trends in the I(1) Versus I(2) Model: An application to aggregate money holdings. Economic Reviews 13(2): 151-178.

- (1995). Do Purchasing Power Parity and Uncovered Interest Rate Parity Hold in the Long Run? An Example of Likelihood Inference in a Multivariate Time-Series Model. Journal of Econometrics 69: 211-240.

- (1998). A structured VAR for Denmark Under Changing Monetary Regimes. Journal of Business and Economic Statistics, 16(4): 400-411.

- (1999). Models and relations in Economics and Econometrics. Journal of Economic Methodology 6(2): 259-290.

Kuhl, M. and Schmitz, P. M. (1998). Dynamic Linkages between Macroeconomic and Agricultural Sector Variables in Germany. In Brockmeier, M, Francois, J.F., Hertel, T. W. and P. M. Schmitz (eds). Economic Transmission and the Greening of Policies- Modeling New Challenges for Agriculture and Agribusiness in Europe. Kiel.

Kwiatkowski, D., Phillips, P., Schmidt, P. and Shin, Y. (1992). Testing the Null Hypothesis of Stationarity Against the Alternative of Unit Root. Journal of Econometrics 54: 159-178.

Larue, B. and Babula, R. A. (1994). Evolving Dynamic Relationships between the Money Supply and Food-Based Prices in Canada and the United States. Canadian Journal of Agricultural Economics 42: 159-176.

Longmire, J. and Morey, A. (1983). Strong Dollar Dampens Demand for US Farm Exports. FAER Report $n^{\circ} 123$, USDA, Washington DC.

Lütkepohl, H. (1993). Introduction to Multiple Time Series, Spring Verlag, Berlin.

Lütkepohl, H. and Reimers, H. E. (1992). Impulse Response Analysis of Cointegrated Systems. Journal of Economic Dynamics and Control 16:53-78.

Matthews, H. and Hanrahan, K. (1996). Measurement of the Effect of Macroeconomic Policy on Irish Agriculture, 1973-1992. Paper presented at the VIII. EAAE Congress in Edinburgh/Scotland.

Moscconi, R. (1998). MALCOLM: The Theory and Practice of Cointegration Analysis in RATS. Cafoscarina, Venezia (http://www.greta.it/malcolm).

Orden, D. and Fackler, P.L. (1989). Identifying Monetary Impacts on Agricultural Prices in VAR Models. American Journal of Agricultural Economics 71: 495-502.

Robertson, J. C. and Orden, D. (1990). Money Impacts on Prices in the Short and Long Run: Some Evidence from New Zealand. American Journal of Agricultural Economics 72: 160-171.

Schuh, G. E. (1974). The Exchange Rate and U.S. Agricultural. American Journal of Agricultural Economics 56:1-13.

Sims, C. (1986). Are Forecasting Models Usable for Policy Analysis?. Federal Research Bank of Minneapolis . Quarterly Review 10: 2-16. 
Taylor, J. S. and Spriggs (1989). Effects of the Monetary Macroeconomy on Canadian Agricultural Price. Canadian Journal of Agricultural Economics 22: 278-289.

Thraen, C. S, Hwang, T. C. and Larson, D. W. (1992). Linking of U.S. Monetary Policy and Exchange Rates to World Soybean Markets. Agricultural Economics 6: 365-384.

Tweeten, L. (1980). An Economic Investigation of Inflation Passthrough to the Farm Sector. Western Journal of Agricultural Economics 5: 89-106. 